\title{
The Similarity in Orientation for Ancient Construction at Mesoamerica and Three World Cases
}

\author{
G. Herrera-Sánchez, E. J. Suárez-Dominguez*, E. Arvizu-Sánchez, R. R. Gallegos-Villela, \\ L. G. Valle-Chavarría, M. E. Calvillo-Villicaña
}

Faculty of Architecture, Design and Urbanism, Autonomous University of Tamaulipas, Circuito Interior S/N. Tampico, Tamaulipas, México

Received April 8, 2021; Revised May 28, 2021; Accepted June 20, 2021

\section{Cite This Paper in the following Citation Styles}

(a): [1] G. Herrera-Sánchez, E. J. Suárez-Dominguez, E. Arvizu-Sánchez, R. R. Gallegos-Villela, L. G. Valle-Chavarría, M.E. Calvillo-Villicaña, "The Similarity in Orientation for Ancient Construction at Mesoamerica and Three World Cases," Civil Engineering and Architecture, Vol. 9, No. 5, pp. 1456 - 1464, 2021. DOI: 10.13189/cea.2021.090518.

(b): G. Herrera-Sánchez, E. J. Suárez-Dominguez, E. Arvizu-Sánchez, R. R. Gallegos-Villela, L. G. Valle-Chavarría, M. E. Calvillo-Villicaña (2021). The Similarity in Orientation for Ancient Construction at Mesoamerica and Three World Cases. Civil Engineering and Architecture, 9(5), 1456 - 1464. DOI: 10.13189/cea.2021.090518.

Copyright $\odot 2021$ by authors, all rights reserved. Authors agree that this article remains permanently open access under the terms of the Creative Commons Attribution License 4.0 International License

\begin{abstract}
The study of the pyramids has attracted attention for several centuries because of the construction itself and its positions. We try to understand their formal and geospatial position and implications. There are various hypotheses about the design of them, from the mystical sphere to mathematical analysis. In this research, we carried out a study of the orientation presented in various prehispanic buildings in Mexico, as a part of Mesoamerica; we selected the most important ceremonial places or pyramids and different cultures, including the last one called "Aguada Fenix" that may produce the first knowledge. Separately, we consider three similar cases, Iraq, Iran, and Egypt, as ancient initial constructions. The research shows that orientation prevails from the visualization of the sunset from the location selected by the Mesoamerican culture under a particular specific translational earth position. However, some cultures prioritized solstice sunrise-facing constructions. It does not necessarily imply that they knew explicitly about the cardinal points: the position of the sun may be sufficient. The Giza Pyramid case is analyzed under this perspective, proposing that the arrangement was carried out by following the line from sunrise to sunset through the drawing of lines from the same point, allowing the largest sunny area during the year.
\end{abstract}

Keywords Pyramid Location, Sunrise-Sunset in Cultures, Mesoamerican Culture, Aguada Fenix Orientation

\section{Introduction}

It has been suggested astronomical reasons for the pyramids' orientation, influenced by solar conditions according to Sprajc, I. 2018 [1]. At the archaeological site of Tula, the importance is set to the observer's relative position and the reference point with precise alignments with the surrounding [2,3].

Some directions are considered distinct such as north and solstices as well as lunar events [4], although other locations have also been found to be reference points at the time of construction as well as hypotheses mythological like that of the five suns [5] or the availability of resources such as water [6].

Although the inside-arrangement of pyramids (such as those found in Teotihuacan in Mexico) is found around symbolic meaning, we find other possible criteria as geometry and the origin of city planning $[7,8]$; in other cases like the Pyramid of Niches in the Archaeological Zone of Tajin some authors believed that ritual practices are related to location and orientation [6,9].

Interestingly, there is a relationship between the pyramids' design decisions, which may have been transmitted throughout civilizations. For example, the Toltec style of Chichen Itzá in Yucatan, Mexico, preceded the Tollan phase in Tula, Hidalgo, with similar features 
among the cities that originated the Mayans [10]; this is strengthened by the iconography that has been shared even geographic and temporal differences in location. In a recent study, we find a Mesoamerican Place called Ceremonial Structure "Aguada Fénix" being maybe the oldest place in Mexico with social equalities [11] and allowing knowledge sharing to other cultures.

In the present work, a study of the orientation presented in various prehispanic constructions located in Mexico is carried out, and three similar cases in Irák, Iran, and Egypt; besides, the Giza Pyramid case is analyzed under this perspective is also shown.

\section{Methods}

The most emblematic buildings built in the prehispanic era in Mexico were selected: Archaeological area of Tula, Teotihuacan, Archaeological area of Cholula, Archaeological area of Toniná, Great Pyramid of Uxmal, Temple of Kukulkan in Chichen Itzá, Archaeological area of Tajín, Archaeological area of Cañada de la Virgen. Three essential cases from the ancient world were analyzed separately: Chogha Zanbil, Zigurat of Ur, and Giza's Great Pyramid.

Geographical location was performed using Openstreetmap.org 2020 [12] because it has shown reliable results in cities' analysis [13]. The study was then carried out regarding the selected point's location and the solar path with the sunearthtools.com 2020 tool [14].
From locations with sunrise and sunset, we determined the orientation of elements, considering information from literature, in addition to analyzing the geometry presented. All images were obtained from open access Openstreedmap and sunearthtools.

\section{Results and Discussion}

Mysticism in construction still accompanies relevant characteristics in the spatial placement of buildings and the interior design [15].

We found the solar curve from the selected places. In all cases, we found that there is a relationship exclusively with sunrise or sunset. Figure 1 shows the first case of analysis corresponding to Teotihuacan, selecting the Pyramid of the Sun as the City's reference point, finding a sunset-facing pyramid. In all cases, we found to be the June solstice sunset or sunrise.

Teotihuacán considers it is surrounded by a set of mountains so that the perception of the sunset can move according to the viewing point. However, even with this, an orthogonal geometry is presented. Regardless of its location, the orientation seems to optimize the illuminated surface area throughout the day. It was a repetitive factor in most of the cases studied in Mexico.

Notice that in almost all archaeological centers in Mexico are found outside the urban layout, as in the Teotihuacan case.

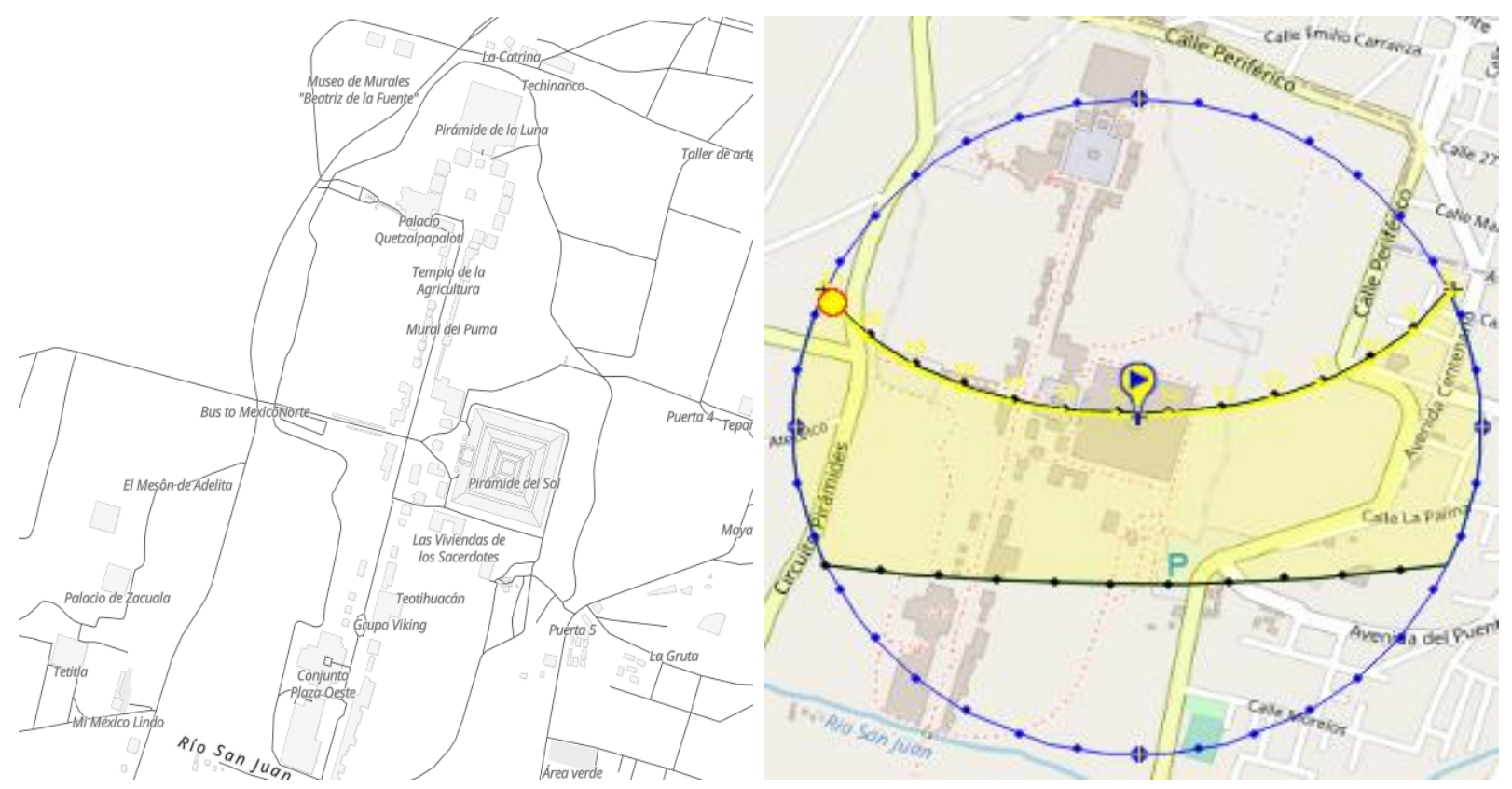

Figure 1. Teotihuacán and its solar curve (sunearthtools.com) 


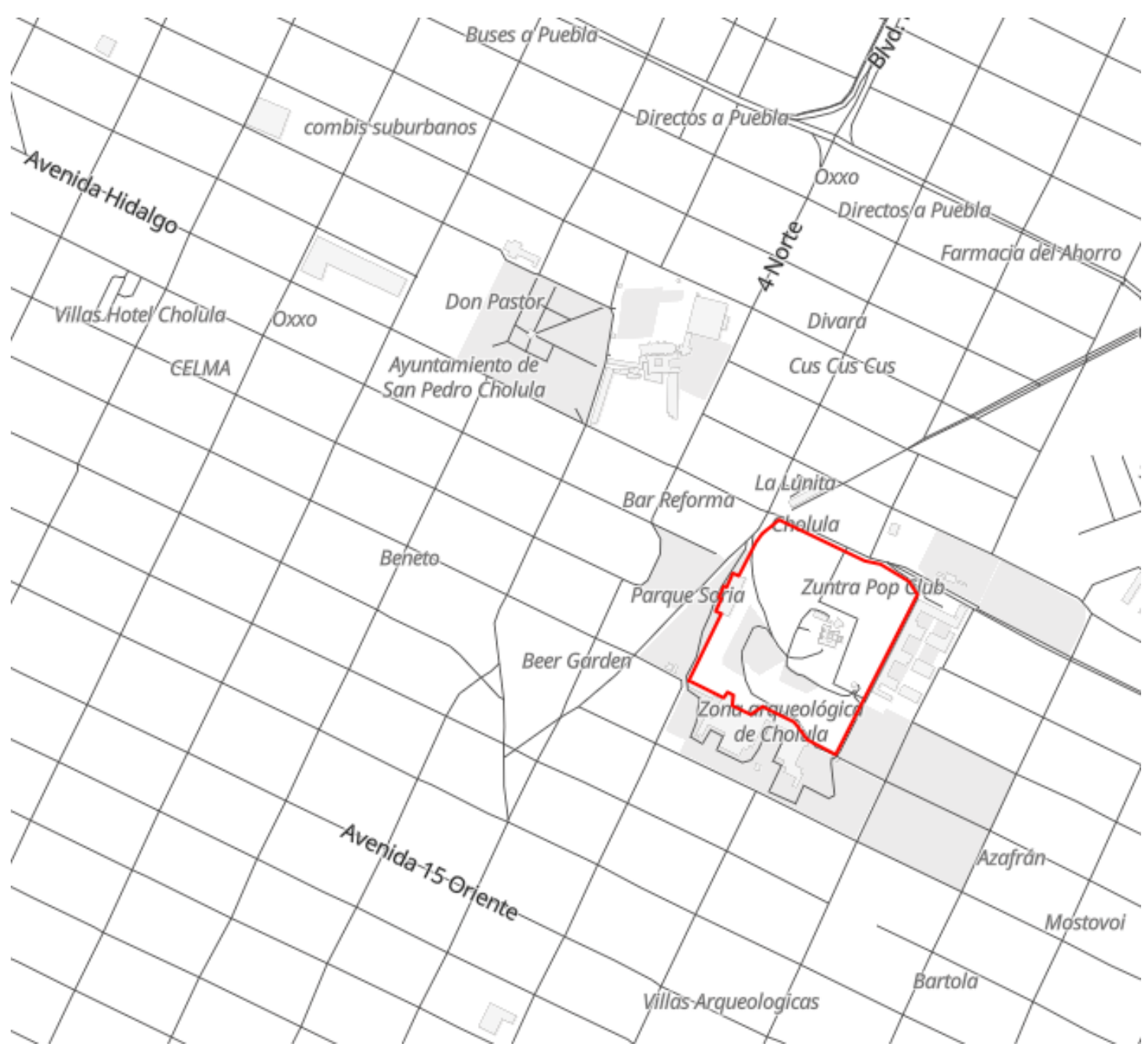

a

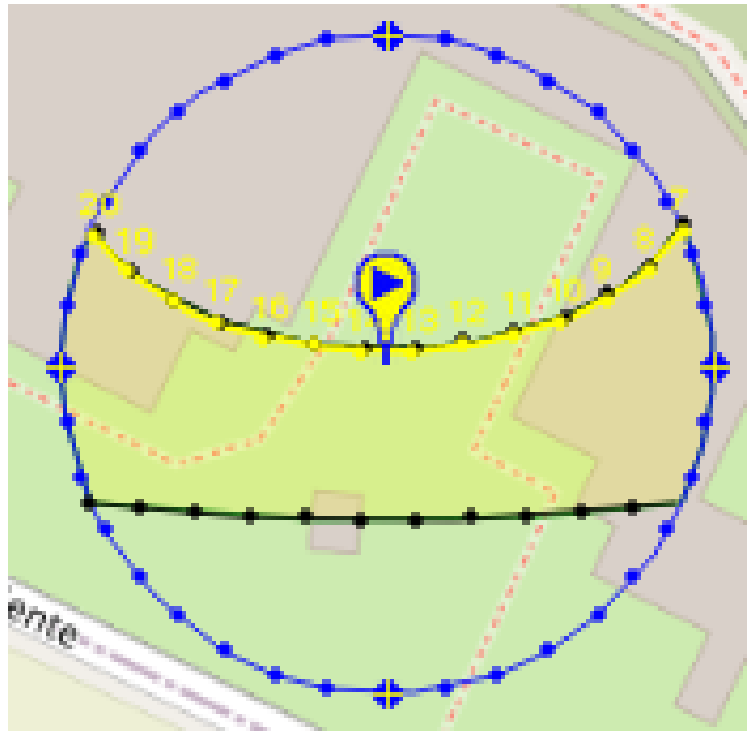

b

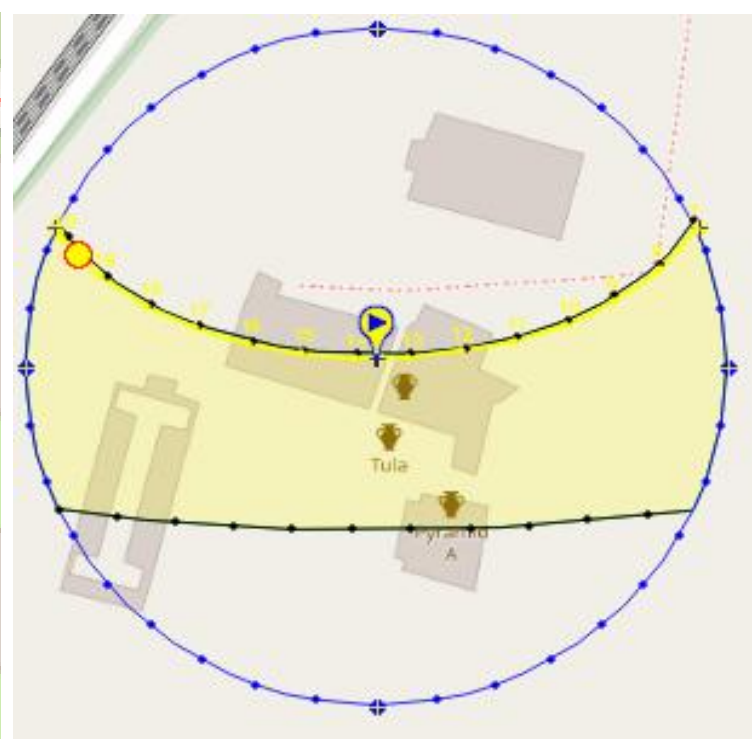

Figure 2. a. Cholula Archaeological Zone with b. solar movement similar to c. Tula Archaeological Zone (sunearthtools.com) 
Figure 2 shows the example of the Cholula archaeological zone; this is similar to the Tula zone, which, although spatially more than $180 \mathrm{~km}$ apart, appears to continue optimizing the exposed area.

Periods in these three cases overlapped each other, with the possibility of interaction and communication between individuals. For the Cholula case.

The Tula archaeological place is out of the city, but for Cholula, we found an urban arrangement that preserves the initial layout. In this case, Colonialism used as foundations the old constructions and took advantage of the rock of the buildings.

Some location criteria, urban design, and architectural, geographical position were born due to the analysis of ancient constructions [16] derived from an analysis of the temporal evolution of buildings.

When moving towards the south of the country, we found similar cases; for example, Figure 3 shows the
Toniná Archaeological Zone in Chiapas and Figure 3b. Shows to Uxmal, locating the point of reference in the Great Pyramid. In the first case, there is an exact situation towards sunset. In the second case, some constructions orientation, such as the Governor's Palace in the archaeological zone of Uxmal, are towards evening. Still, the main pyramid has a rotation considering this axis less than 5 .

There are other, more complex cases. Figure 4 shows the Archaeological Zone of Tajín, towards the northeast of Mexico; many buildings are challenging to locate a specific orientation. Although biased towards the sunset, the selected constructions could have a direction, possibly more related to the hills surrounding the City, and its rugged nature, giving each one of them a probable meaning depending on the different circumstances in which it was created.

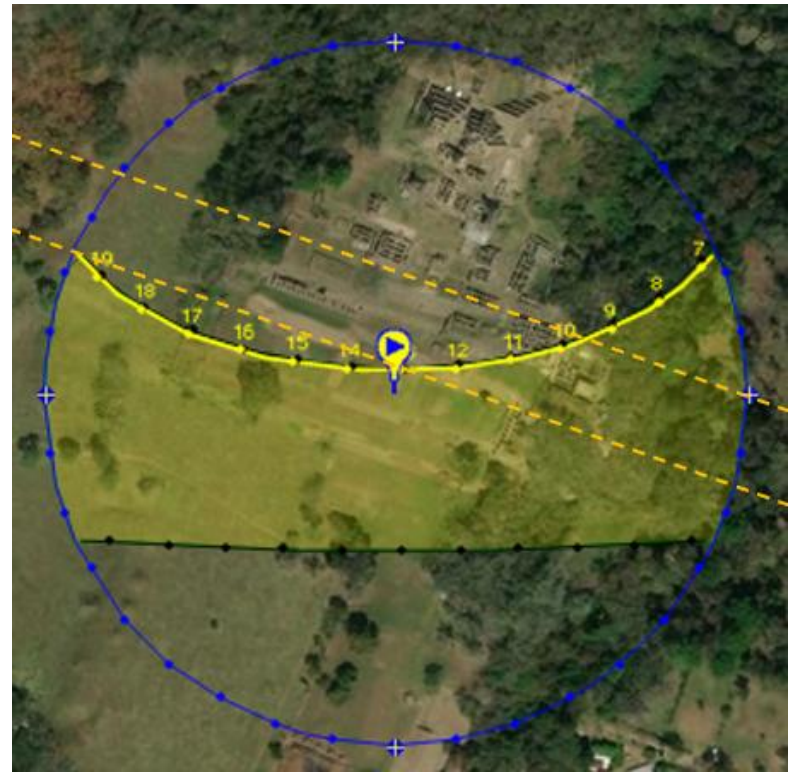

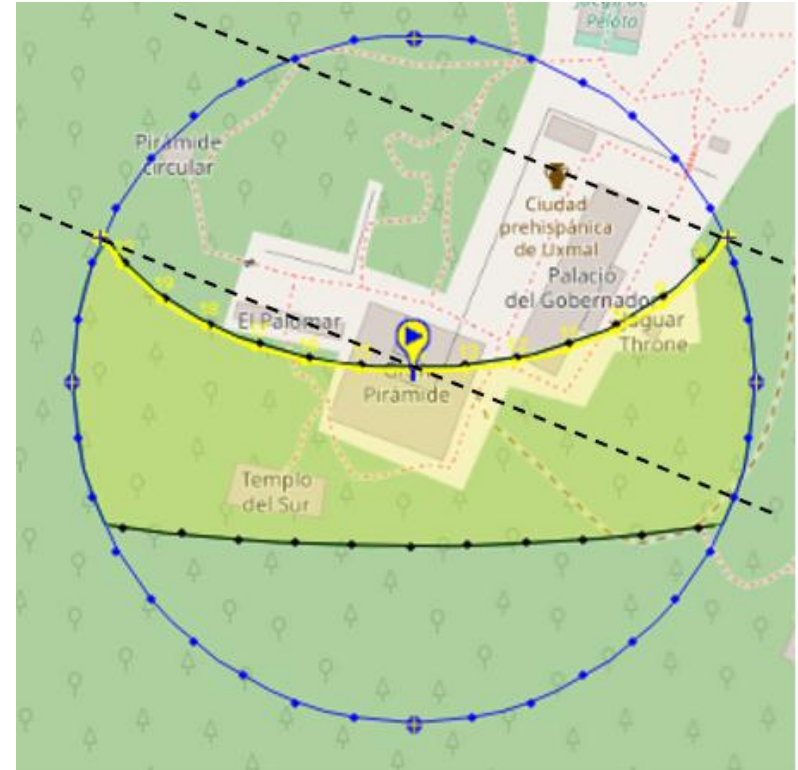

Figure 3. a. Toniná Archaeological Zone and b. Great Pyramid of Uxmal (sunearthtools.com) 

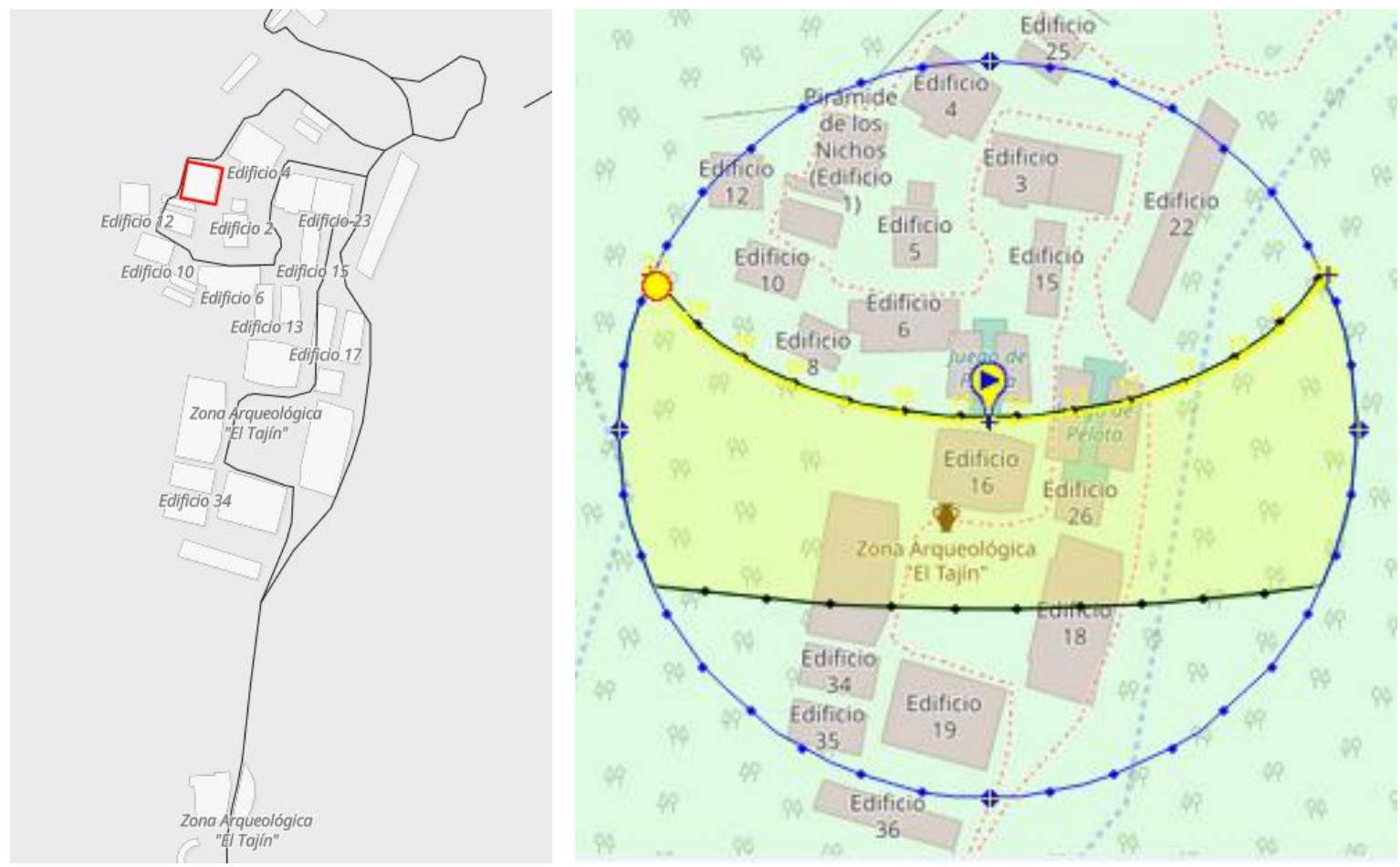

Figure 4. Archaeological Zone of Tajin (sunearthtools.com)
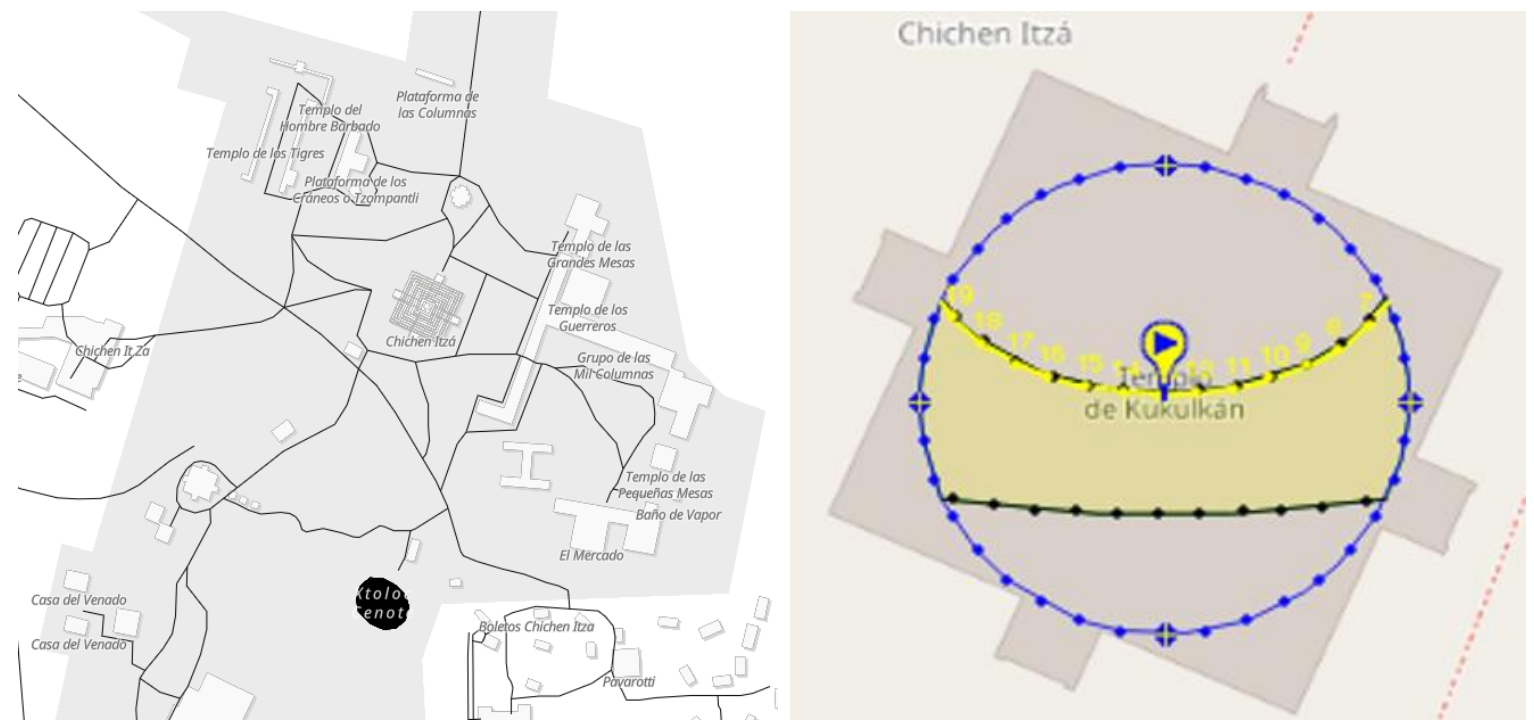

Figure 5a. Chichen Itzá Archaeological Zone centered on the Temple of Kukulkan

Among the cases analyzed, one oriented towards dawn instead of sunset, which is not common in the main buildings or prehispanic cities. In another zone in the country's west, we can find the Archaeological Zone of Cañada de la Virgen (Guanajuato, Mexico). It is essential to highlight the location on the Mesoamerican Frontier. In this case, we found pyramids in an isolated place, but it remains the pyramid orientation in the houses near this.

In the southeast of Mexico, we see Chichen Itzá, shown in Figure 7, centered on the Kukulkan Temple, shows the same orientation from the observer's point. Nevertheless, it appears that some buildings are orientated from the zenith (i.e., Figure $4 b$ or Figure $8 b$ ).

The last place analyzed in Mexico was the Ceremonial Structure "Aguada Fénix" shown in Figure 6, where we can notice that position is similar to the other ancient places. Maybe this place, discovered in 2020 (Inomata, T. et al. 2020) is the first place in Mexico with this orientation, and the knowledge about buildings position criteria was transmitted over time to the different cultures. 


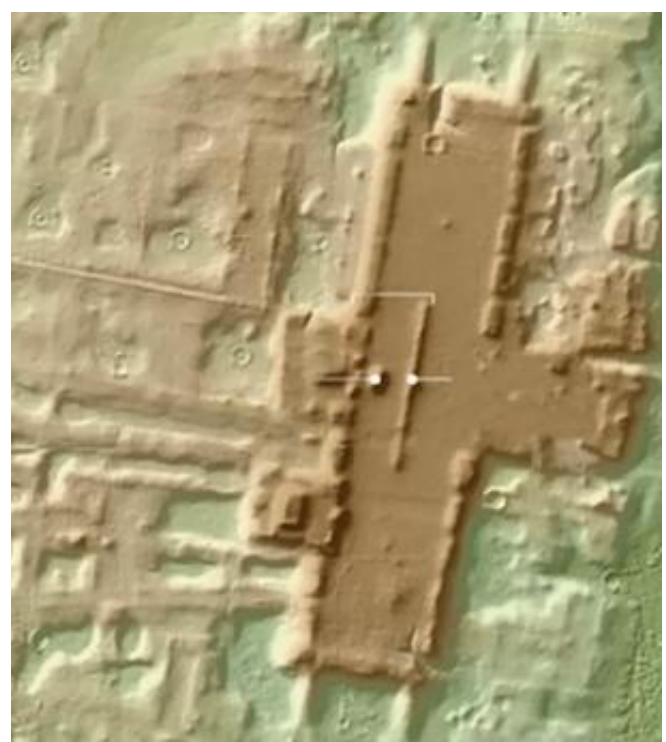

a

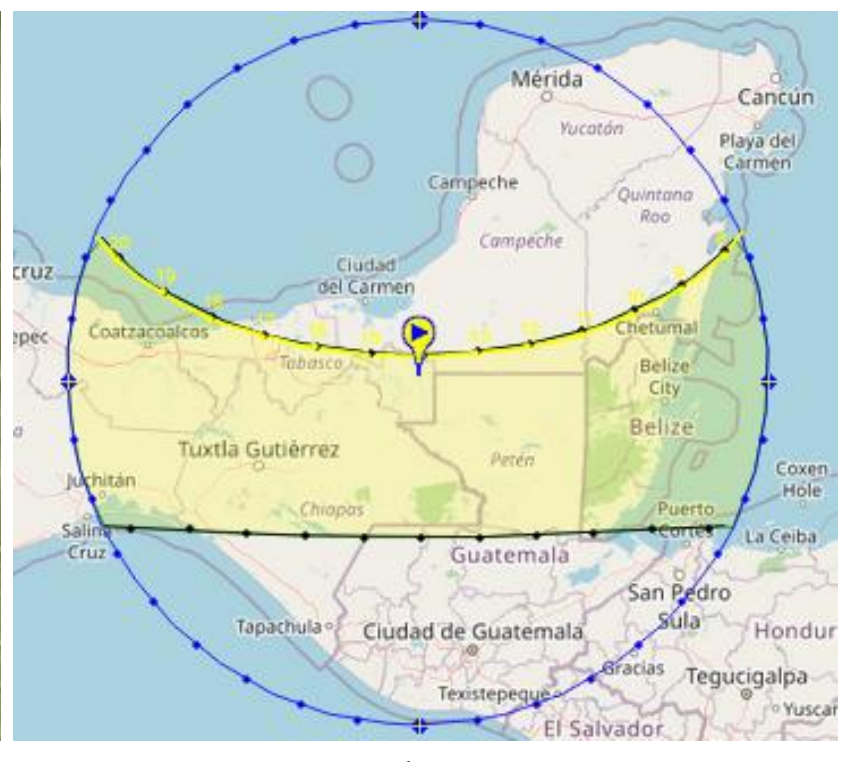

$\mathrm{b}$

Figure 6. Ceremonial Structure "Aguada Fénix" a. localization in México and solar and b. Monumental Architecture "Aguada Fenix" published in Nature (Inomata, T. et al. 2020)

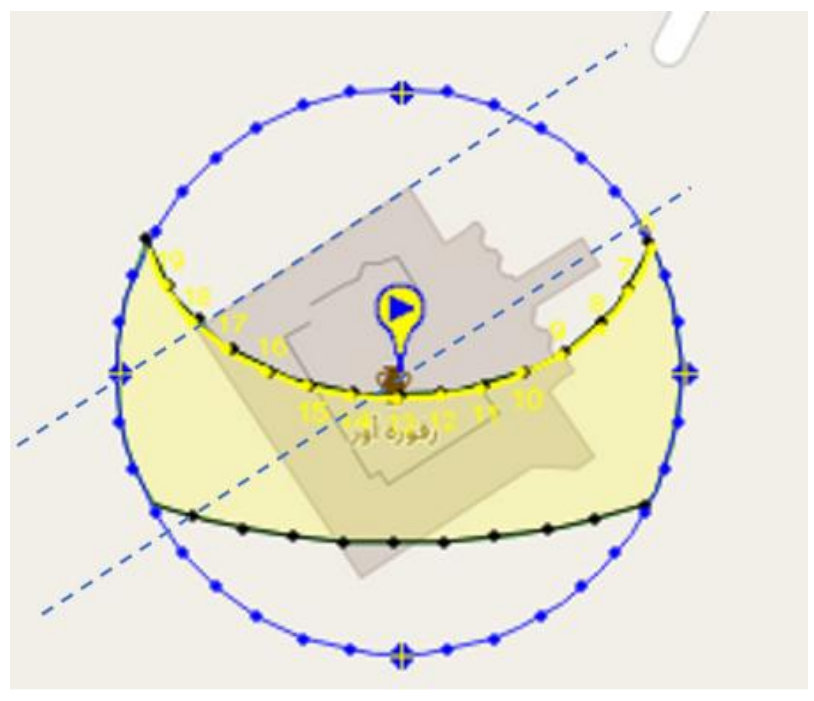

a

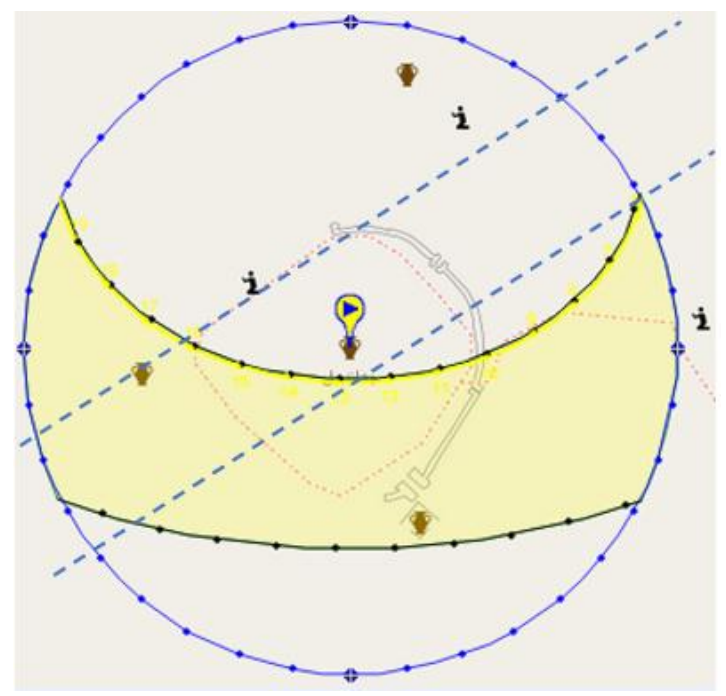

$\mathrm{b}$

Figure 7. Reference points for the location a. Ziggurat of Ur b. Chogha Zanbil (sunearthtools.com)

We performed a similar analysis to three representative cases outside of Mexico located above the Equator, finding the same results, following the sun's curvature during the June solstice but with a direction towards sunrise and from sunset.

Figure 7 presents the selection of the orientation from two criteria. Figure 7a. corresponds to the Ziggurat of Ur, observing that it coincides with the sunrise considered from the observer's position. At the same time, in Figure 7 b., we show the case of Chogha Zanbil, observing that orientation coincides at sunset concerning the zenith.

Although the considerations for which one decision about orientation may refer to mystical issues mentioned by other authors, it could be a coincidence. It would be the simplest explanation for the establishment of the placement of the ancient constructions.

It is important to note that for almost all the cases from Mexico mentioned in this work, we saw a marked arrangement of the main buildings. The prevailing winds in summers strike directly at an angle of ninety degrees concerning the line of the side facade. In this work, we also introduce a possible comfortable meaning in design for the cases of the important buildings near pyramids, where governors or kings were living.

This is not applied to the ancient cases for the showed in Figure 7 and 8, where geographic orientation predominates

Finally, the analysis was performed to see the Giza Pyramid's similarity, as shown in Figure 8, showing the location. 
Figure $8 \mathrm{~b}$ includes the outline of one of the sides of the base of the pyramid. Currently, it is hypothesized that the orientation is to the north. Still, it may be derived more from the decision to base the line exclusively by sunrise and sunset. Direction is possibly drawing a line from the same point towards sunrise and sunset on the same day, and then two ends are joined at the same distance from the observer on the line.

It was probably considered that in this way, the sun gives one side of the pyramid a higher amount of time throughout the year; this is also displayed in the king's chamber, which is not in the center but is offset towards the sun side.

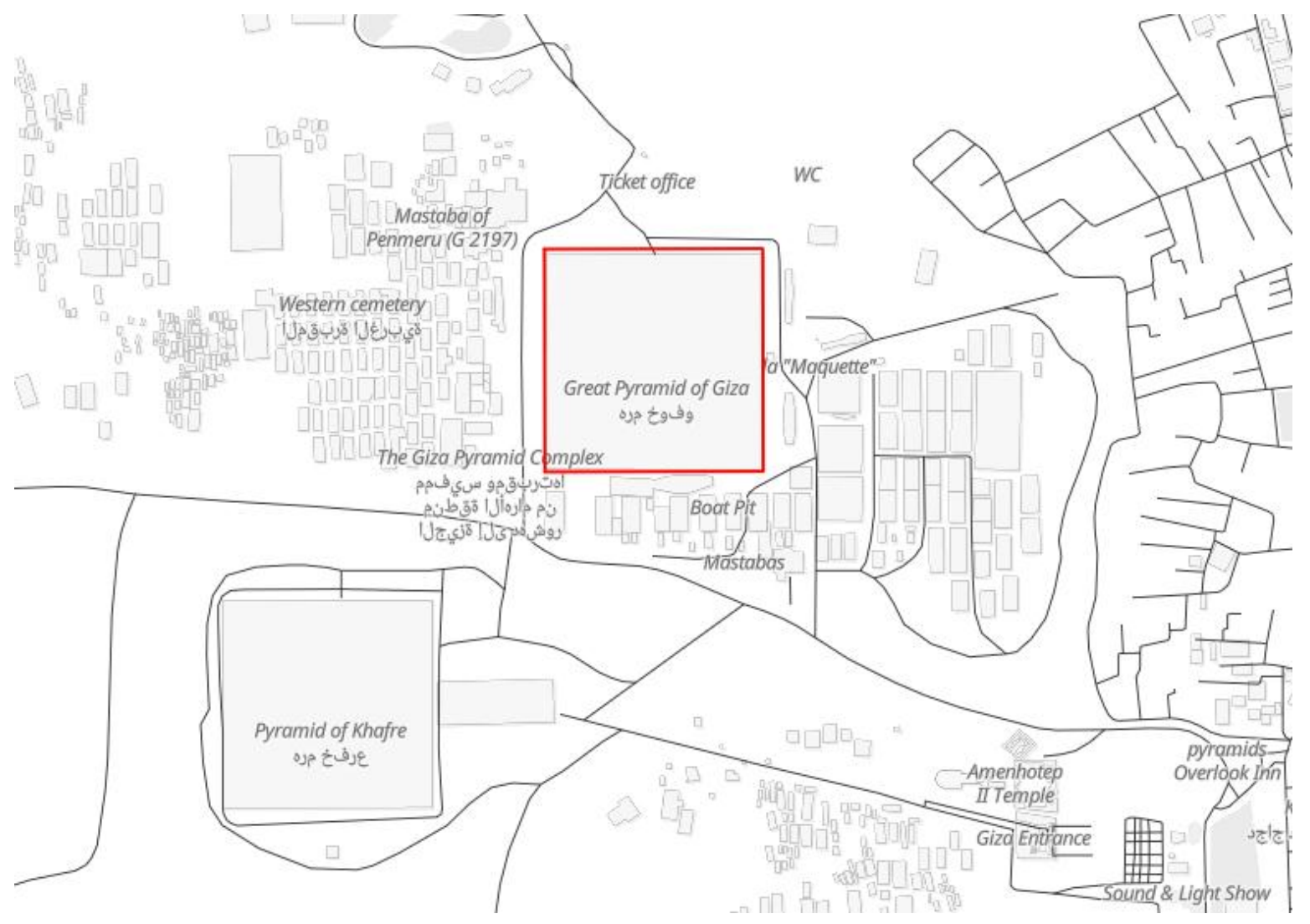

a

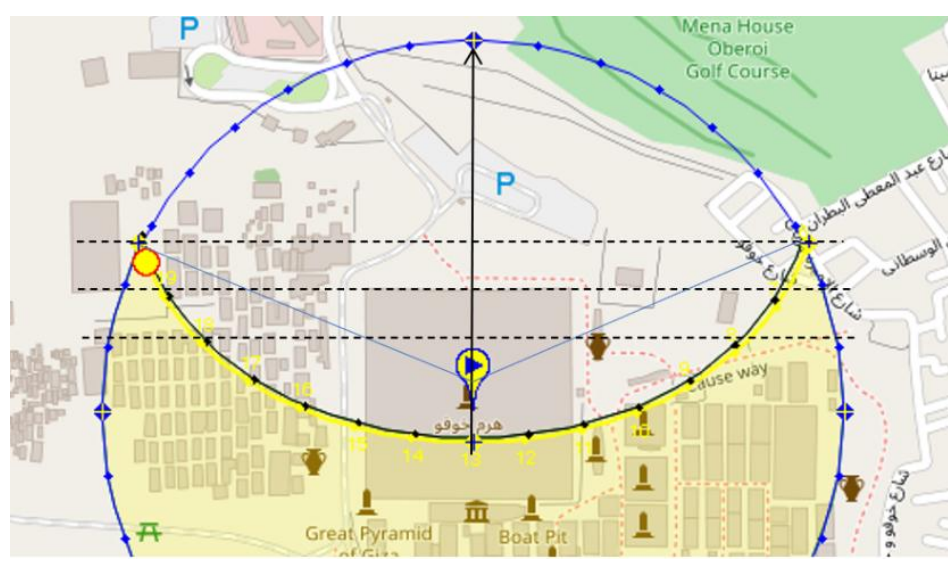

b

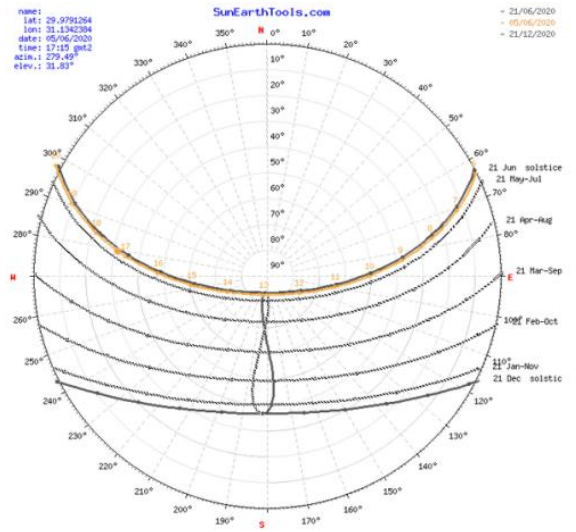

$\mathrm{c}$

Figure 8. Location of the Great Pyramid of Giza a. view of the set of Giza pyramids b. using sunrise and sunset to set the reference axis and c. solar map (sunearthtools.com) 
Table 1. Summary of results obtained from orientation

\begin{tabular}{|c|c|c|c|}
\hline Place & Country & Cronología & $\begin{array}{c}\text { Orientation (June } \\
\text { solstice) }\end{array}$ \\
\hline Archaeological area of Tula & & $800-1200 \mathrm{AC}$ & Sunset \\
\hline Teotihuacán & & $150 \mathrm{BC}-1200 \mathrm{AC}$ & Sunset \\
\hline Archaeological area of Cholula & & $650 \mathrm{BC}-1521 \mathrm{AC}$ & Sunset \\
\hline Archaeological area of Toniná & & $300 \mathrm{BC}-1528 \mathrm{AC}$ & Sunset \\
\hline Gran Pirámide de Uxmal & México & $600-1000 \mathrm{AC}$ & Sunset \\
\hline Templo de Kukulkan en Chichen Itzá & & $1500 \mathrm{AC}$ & Sunset \\
\hline Archaeological area of Tajín & & $300-1200 \mathrm{AC}$ & Sunset \\
\hline Ceremonial Structure "Aguada Fénix" & & $1000-350 \mathrm{BC}$ & Sunset \\
\hline Archaeological area of Cañada de la Virgen & & $540 \mathrm{BC}-1050 \mathrm{AC}$ & Sunrise \\
\hline Chogha Zanbil, & Iran & $1250 \mathrm{BC}$ & Sunrise \\
\hline Zigurat of Ur & Irak & $2050-2030 \mathrm{BC}$ & Sunrise \\
\hline Great Pyramid of Giza & Egypt & $2580-2560 \mathrm{BC}$ & Sunrise-Sunset \\
\hline
\end{tabular}

Therefore, the pyramid's most crucial facade may not be the one currently considered, but rather the one located to the south. It is also important to note from the solar chart that one of the advantages of the geographical point where Giza is located also coincides with an ellipse formation, as shown in Figure 8c. In summary, we hypothesized that the north's apparent orientation is a coincidence of the decision to place a sunrise-sunset baseline during the summer solstice, which coincides with other possible spatial considerations.

Finally, Table 1 summarises the results found in this work with the criteria of orientation. It can be seen that it is possible to see a better classification only with sun direction.

\section{Conclusions}

The pyramids from the Archaeological area of Tula, Teotihuacan, Cholula, Tonina, Uxmal, Tajin, and Temple of Kukulkan at Chichen Itza have an orientation to summer solstice sunset, allowing higher surface area lighting of buildings concerning other directions. That is, for one of nine archaeological zones, other characteristics should have been taken into account, like confortability or the prevailing winds in certain seasons of the year.

For Chogha Zanbil and Ziggurat of Ur are different, where they are located toward the sunrise; in the case of the Great Pyramid of Giza, it is found that the orientation that has the most sunlight is the one that has as its baseline that traces from sunrise to sunset, which can be done by directing a straight line from the same point towards the exit and sunset.

Finally, for the cases of Mexico, we found that the last discovery from a 2050-2030BC Mesoamerican place called Ceremonial Structure "Aguada Fénix" has a sunset orientation too, being possibly the first place sunset oriented in this country.

\section{Acknowledgments}

This research was supported by Universidad Autónoma de Tamaulipas and PROFEXCE program.

\section{REFERENCES}

[1] Šprajc, I. Zenith and Nadir "Passages of the Sun in Mesoamerica". Journal of Skyscape Archaeology, Vol. 4 No.1, pp. 108-117, 2018. https://doi.org/10.1558/jsa.36092

[2] Tichy, F. (1976). "Orientación de las pirámides e iglesias en el altiplano mexicano" Vol. 4. Fundación Alemana para la Investigación Científica: German.

[3] Healan, D. M. "The Archaeology of Tula, Hidalgo, Mexico". Journal of Archaeological Research, Vol. 20, No. 1, pp. 53-115, 2012. https://doi.org/10.1007/s10814-011-9 $052-3$

[4] Šprajc, I., \& Nava, P. F. S. "Equinoxes in Mesoamerican Architectural Alignments: Prehispanic Reality or Modern Myth?". In Ancient Cosmologies and Modern Prophets: Proceedings of the 20th SEAC Conference (pp. 319-337) 2013.

[5] Carlotto, M. "On the Alignment and Possible Origin of Certain Ancient Sites in Mesoamerica". Available at SSRN 3564322, 2020.https://papers.ssrn.com/sol3/papers.cfm?ab stract_id $=3564322$

[6] Evans, S. T. "Location and orientation of Teotihuacan, Mexico: Water worship and processional space". Occasional Papers in Anthropology at Penn State, No. 33, pp. 52-121, 2016. https://journals.psu.edu/opa/article/view/ 60110

[7] Argote, D. L., Tejero-Andrade, A., Cárdenas-Soto, M., Cifuentes-Nava, G., Chávez, R. E., Hernández-Quintero, E., ... \& Ortega, V. "Designing the underworld in Teotihuacan: Cave detection beneath the moon pyramid by ERT and ANT surveys". Journal of Archaeological Science, $118,105141.2020$. 
[8] Friedl, A. J. "The Pyramids and Temples of Angamuco (Michoacán, Mexico): Decoding Meaning Through Spatial Analysis of Form, Scale, and Directional Orientation" (Doctoral dissertation, Colorado State University. Libraries). 2019.

[9] Iwaniszewski, S. "La Pirámide de los Nichos en El Tajín: calendario, ritual, simbolismo mítico". Revista Cosmovisiones/Cosmovisões, Vol. 1 No. 1, pp. 106-120, 2020. http://siac.fcaglp.unlp.edu.ar/V1N1/iwaniszewskiV1 N1.pdf

[10] Jordan, K. "From Tula Chico to Chichén Itzá: Implications of the Epiclassic Sculpture of Tula for the Nature and Timing of Tula-Chichén Contact". Latin American Antiquity, Vol.27 No. 4, pp. 462-478, 2016. Doi.org/10.7183/1045-6635.27.4.462

[11] Inomata, T., Triadan, D., López, V. A. V., Fernandez-Diaz, J. C., Omori, T., Bauer, M. B. M., ... \& Nasu, H. "Monumental architecture at Aguada Fénix and the rise of Maya civilization". Nature, No. 582, pp. 1-4. 2020. https://doi.org/10.1038/s41586-020-2343-4

[12] Openstreetmap.org (2020) Recuperado el 06 de enero de
2020. Available at: https://www.openstreetmap.org/

[13] Ferster, C., Fischer, J., Manaugh, K., Nelson, T., \& Winters, M. "Using Open Street Map to inventory bicycle infrastructure: A comparison with open data from cities". International Journal of Sustainable Transportation, Vol. 14 No. 1, pp. 64-73, 2020.

[14] Sunearthtools.com. 06th january 2020. Available at: https://www.sunearthtools.com/

[15] Nuryanto, Ngakan Ketut Acwin Dwijendra, Syamsul Alam Paturusi, I Made Adhika, "Technic and Mystics of Tukang Wangunan in Sundanese Traditional Houses in Indonesia (Case Study: Baduy Tribe Community-Banten)," Civil Engineering and Architecture, Vol. 9, No. 2, pp. 533 - 544, 2021. DOI: $10.13189 /$ cea.2021.090226.

[16] Christie Lanjing Entika, Shahrin Mohammad, Mohd Khata Jabor, Sharifah Osman, "Reimagining Civil Engineer's Managerial Role as an Entrepreneurial Function in the Production System of a Construction Project," Civil Engineering and Architecture, Vol. 8, No. 4, pp. 417 - 425, 2020. DOI: $10.13189 /$ cea.2020.080403. 